\title{
Simone Mariani \\ Recruitment in invertebrates with short-lived larvae: the case of the bryozoan Disporella hispida (Fleming)
}

Received: 25 June 2002 / Revised: 28 October 2002 / Accepted: 28 October 2002 / Published online: 19 December 2002 (C) Springer-Verlag and AWI 2002

\begin{abstract}
Temporal and spatial recruitment patterns of the cyclostome bryozoan Disporella hispida were monitored using settlement plates arranged along three benthic communities of an artificial reef at Blanes (NE Spain, NW Mediterranean). At the study site, the species mainly inhabits semi-obscure caves. By studying recruitment over one year I first inferred the larval release period for D. hispida and described its temporal occurrence in the communities and stations studied. Secondly, I attempted to determine whether the predicted restricted dispersal may account for the species' distribution at the study site. To this purpose, I compared the distribution of early recruits ( 15 days old) with that of adults. I also investigated environmental factors which may affect the extent of larval dispersal, and described the effects of post-recruitment processes occurring over a 4-month period. The brooding period, inferred from the study of early recruitment, was linked to spring-increments and autumn-decrements of water temperatures. Early recruits were distributed non-randomly in the communities and stations studied, being most abundant in the habitats where adults live. Strong hydrodynamic events seemed to modify this pattern, allowing recruitment out of the parental communities, and may hinder settlement. Postrecruitment mortality events were likely to prevent colonisation of habitats where the species do not live. Overall, philopatry and low post-recruitment mortality in the parental communities appeared to be the main mechanisms determining the distribution of $D$. hispida at the study site.
\end{abstract}

Communicated by E. Rachor

S. Mariani (

Centre d'Estudis Avançats de Blanes,

C/ACC,

Cala S Francesc 14, 17300 Blanes, Spain

e-mail: simone@ceab.csic.es

Tel.: +34-972-336101, Fax: +34-972-337806
Keywords Bryozoa Cyclostomata Philopatry ·

Habitat choice Post-recruitment mortality ·

Competition · Mediterranean Sea

\section{Introduction}

Reproductively active adults largely determine the distribution of larvae, and settlement is most likely to occur near parents in sessile invertebrates with short-lived larvae (e.g. Gerrodette 1981; Keough 1989; Hurlbut 1991). This acknowledged pattern depends on larval features such as morphology (e.g. Turon and Vázquez 1996) and swimming behaviour (e.g. Fadlallah and Pearse 1982), which hinder long-distance dispersal and favour larval retention near parental habitats. Nevertheless, influences during the planktonic period can alter this pattern. Hydrographic events (e.g. currents, tides, waves; see Young and Chia 1987; Dirnberger 1993) may result in larval transport far away from parental habitats. However, many lecithotrophic larvae of colonial invertebrates have such short planktonic periods (in the range of a few hours) that they are most likely to settle before currents or other hydrodynamic events could carry them away (Jackson 1986; Davis and Butler 1989).

Colonial bryozoans are an example of sessile invertebrates producing larvae with short planktonic periods. In particular, most cyclostomes and cheilostomes release lecithotrophic short-lived larvae with limited dispersal capabilities (Jackson 1985, 1986; Temkin and Zimmer 2002),

In the laboratory, coronate larvae of many colonial bryozoans settle within a few hours of release (Ryland 1976; Jackson 1985; Keough 1989), and settlers rapidly colonise available substrates (Keough and Downes 1982). Larvae are gregarious at settlement (Ryland 1976; Keough 1984), which occurs in the vicinity of adults mainly due to short dispersal (Keough 1989). Cyclostomes produce lecithotrophic larvae with the simplest structure in marine bryozoa (Ryland 1976). Such larvae are uniformly ciliated coronates, $100-150 \mu \mathrm{m}$ along their 
long axis. They are extremely short lived; some species [i.e. Crisia eburnea (L.)] settle within $15 \mathrm{~min}$ of release in the laboratory (Nielsen 1970). In contrast to the larvae of cheilostomes, those of cyclostomes (i.e. Tubulipora) do not bear eyespots (Ryland 1976), and responses to light stimuli are unknown.

Under field conditions, larval dispersal and settlement can be studied either through direct observation of freeswimming larvae or by recording recruitment. Underwater observation of larval swimming and settlement can be performed only on larvae visible to the naked eye (see Olson 1985; Stoner 1990; Carlon and Olson 1993). However, most coronate larvae are virtually impossible to observe directly because of their reduced size, and it is difficult to record settlement. Hence, perhaps the most feasible way to infer settlement in marine sessile invertebrates is to study their recruitment (see Zea 1993).

Mediterranean populations of the bryozoan Disporella hispida (Fleming) show a wide distribution, from photophilic habitats such as algal thalli (i.e. Udotea, Halimeda) and seagrass leaves (Posidonia oceanica (L.) Delile; see Zabala 1986), to sciaphilous habitats such as caves (Harmelin 1976). The reproductive period is unknown for this species. A preliminary visual monitoring had revealed that adult colonies of this bryozoan preferentially inhabit semi-obscure caves at the study site.

I monitored temporal and spatial recruitment patterns using settlement plates arranged in the benthic communities of an artificial reef in the NW Mediterranean. By studying recruitment over one year, I first tried to determine the Disporella hispida larval release period. Second, I attempted to determine whether the supposed limited ability of dispersal may account for the species' distribution at the study site. To do so, I compared the distribution of early recruits (15 days old) with that of adults. I also investigated environmental factors that may affect the extent of larval dispersal, and described the effects of post-recruitment processes occurring over a 4-month period.

\section{Materials and methods}

Study site and environmental parameters

The study was conducted along a 65-year-old artificial reef that protects Blanes Harbour (NE Spain, NW Mediterranean Sea). The reef is formed by large $(4 \times 2 \times 1 \mathrm{~m})$ concrete boulders lying on a sandy bottom at $\sim 13 \mathrm{~m}$ depth along the seaward side of a $300-\mathrm{m}$ wall which protects the harbour. The reef is exposed to winds from E-SW quadrants between $\sim 80^{\circ}$ and $\sim 225^{\circ}$. The upper sides of the boulders are characterised by a community dominated by photophilic and semi-sciaphilic algae (henceforth PA), while the lateral sides are characterised by a community of sciaphilic algae (SA). Some boulders overlap each other to form small caves. On overhangs and lateral walls of the caves, communities of semi-obscure caves (SOC) dominate (see Mariani et al. 2000; Mariani 2002).

Along the reef, three randomly chosen stations, about $30 \mathrm{~m}$ apart, were established. At each station, one boulder side representative of each community (PA, SA and SOC) was selected on different but neighbouring boulders. Water temperature at the reef was recorded by a scuba diver every 2-3 days between May 1999 and May 2000.
Information on sea conditions was obtained from a buoy located $30 \mathrm{~km}$ from the study site. Hourly data of significant wave heights (mean one-third of the amplitude measured) were first averaged for each day and then for the 15 days corresponding to the periods when the settlement plates were left underwater (see below). Only data corresponding to winds blowing from $80^{\circ} \mathrm{NE}$ to $225^{\circ} \mathrm{SW}$ were used for the 15 -day means because the harbour wall protects the study site from winds from opposite quadrants (principally those blowing from the north).

\section{Adult distribution}

To quantitatively assess the distribution and abundance of adult colonies among stations and communities, I used photographs taken by a Motormarine M II camera (Sea \& Sea) with a close-up lens covering an area of $150 \mathrm{~cm}^{2}$. Twenty photographs were randomly taken in each community and station (see above) on the reef in summer 2000 (the sandy bottoms were explicitly excluded since the species does not colonise such habitats). The photographs were scanned and analysed using a Power PC and the program Adobe Photoshop 5. The number of adult colonies visible in each photograph was recorded. The outline of each colony was traced and the outlined area calculated using the NIH image 1.6 program (public domain). This was done to assess adult percentage cover in each community and station.

\section{Recruitment}

From May 1999 to May 2000 , five $10 \times 10 \mathrm{~cm}$ Plexiglas plates were tied to each of the boulder sides corresponding to the three communities (for the SOC communities either overhangs and lateral walls of the caves were used) at the three stations to measure early recruitment. The plates were arranged at least $20 \mathrm{~cm}$ from each other and were secured by means of elastic bands tied to small holes at the plate corners and to galvanised nails hammered into the boulders. On the upper right corner of each plate a small rectangle was painted with fluorescent enamel $\left(\sim 0.5 \mathrm{~cm}^{2}\right)$ to identify the orientation of the plates on the boulders once in the laboratory.

Each plate set (45 plates) was left in situ for 15 days. After this period, the plates were collected from the field, placed into sealed bowls underwater and transported to the laboratory. Prior to plate removal, a visual estimation of the sediment layer thickness over the plates and the percentage of plate occupied by sediment was made. I scored "sediment present" when sediments (mostly fine sand) covered $>20 \%$ of the plate area and were $\geq 5 \mathrm{~mm}$ thick. Although it was not always possible, I attempted to immediately replace the old plate set with a new one after removal. The number of plate sets used was 17 over the study period.

Once in the laboratory, the plates were examined under a dissecting microscope. All discernible sessile organisms were counted and their positions on the plate recorded using a grid. Early recruits (proancestrulae) of Disporella hispida may be confused with those of other cyclostomes such as Lichenopora and Tubulipora species, which may share the same habitats. However, D. hispida proancestrulae, like adults, show characteristic pointed peristomes (see Zabala 1986), which are distinctive characters for species differentiation. The presence of marks of detached ancestrulae, dead skeletons and ancestrulae hidden under sediment as well as contacts with and possible overgrowth by other organisms were recorded.

\section{Late recruitment, growth and mortality}

In May 2000, after collecting the last set of plates, I randomly chose three plates from each of the communities of station 3 and recorded the number of Disporella hispida recruits and their position on the plates. The plates were reinstalled underwater in their previous position the next day, collected again 3 months later (August), and examined under the dissecting microscope. For 
Disporella hispida, I recorded the presence/absence of those individuals that had been present 3 months earlier. The results of this preliminary experiment (not replicated along stations) indicated that post-recruitment mortality was higher in the PA and SA communities than in the SOC communities. A second trial was carried out in 2001. I secured three plates in each community and station in May (27 plates). The plates were collected from the field after 15 days. All sessile invertebrate recruits (including $D$. hispida) were counted and their positions recorded. The next day, the plates were reinstalled in their previous position on the boulders, re-collected on 25 September, and transported to the laboratory. Prior to plate removal, a visual estimation of the abundance of sediment on the plates was done (see above). In the laboratory, I recorded the numbers of surviving $D$. hispida individuals among those present 4 months earlier. The presence of secondary gemmae or zooids originating from the first ancestrula was also recorded. Moreover, colony diameter, contact with, or overgrowth by algae and invertebrates, and grazing signs were recorded for each surviving D. hispida individual. A semi-quantitative inventory based on the relative abundance was made for other sessile invertebrates and algae.

\section{Data analysis}

To determine differences in abundance among communities for early recruits (15 days) over the sampling period I used a threefactor mixed-model ANOVA. Community (PA, SA and SOC) and time (sampling period; $n=17$ ) were the fixed factors and the sampling station was the random factor.

To estimate abundance of adults among communities and stations I used two-factor mixed-model ANOVAs. This analysis was also used to determine differences among community and stations for the mortality experiment. Sampling station was the random factor and the community was the fixed factor. The null hypothesis was a uniform distribution of early, late and adult stages among communities. Prior to analysis, data were tested for normality (Kolmogorov-Smirnov test) and homogeneity of variances (Cochran's $C$ test). Data were log-transformed where needed. A posteriori multiple comparison of the means was done using the Student-Newman-Keuls (SNK) test $(\alpha=0.05)$.

Density-dependent mortality was assessed by comparing the number of dead recruits of the 3-month plates with the original density of recruits on the 15-day plates, using regression analysis.

\section{Results}

\section{Adult distribution}

The abundance of Disporella hispida varied significantly between communities and stations (Table 1) and adult colonies were exclusively present in the SOC communi- ties (Fig. 1). The abundance in the SOC communities varied depending on the station, resulting in a significant Community $\times$ Station interaction term (Table 1). Station 3 had higher numbers of adults than stations 1 and 2 (SNK test; Fig. 1).

\section{Recruitment}

The early recruitment plates were colonised by different sessile organisms and to different extents depending on season and community. From early June to mid-October, the PA community plates were mostly covered by algal recruits. Presence of sediment was recorded in three of the 15-day trials, in June, August and September, exclusively on the PA community plates. Algal recruits were much fewer on SA and SOC community plates than on the PA plates, and sediment deposition was not observed on the former due to plate slope (vertical surfaces and overhangs). Identification of algal recruits was not feasible to any taxonomic level. The main sessile invertebrates colonising the plates were the polychaetes Pomatoceros triqueter (L.), Spirobranchus polytrema (Philippi), an unidentified Spirorbid, as well as the barnacle Balanus cf. perforatus (Brugiuère), and the cheilostome Schizobrachiella sanguinea (Norman).

Temporal patterns of recruitment, temperature, and significant wave heights over the study period are shown in Fig. 2. Early recruits of Disporella hispida were found throughout the year except for late July and late November 1999. Several recruitment peaks were observed especially in the SOC communities (Fig. 2). The first one occurred in June 1999 followed by a period of very low recruitment. A second recruitment peak was recorded in late October 1999 both in the SA and SOC and, to a much lesser extent, in the PA communities. After an abrupt interruption (see below), another recruitment peak occurred only in the SOC communities. The last peak was registered in late May 2000 almost exclusively in the SOC communities. Although data on wave heights were obtained from a relatively distant buoy, the first high recruitment peak, particularly the peak recorded on the SA plates, corresponded to a period of high waves. On 12 November 1999 a storm was recorded along the northern coast of Catalonia (NW Spain) (Fig. 2). No

Table 1 Analysis of variance of the effects of community and station on adult, early-recruit, and late-recruit abundance

\begin{tabular}{|c|c|c|c|c|c|c|c|c|c|}
\hline \multirow[t]{2}{*}{ Source of variation } & \multicolumn{3}{|l|}{ Adults } & \multicolumn{3}{|c|}{ Early recruits } & \multicolumn{3}{|c|}{ Late recruits } \\
\hline & MS & $F$ & $P$ & MS & $F$ & $P$ & MS & $F$ & $P$ \\
\hline Community (C) & 24.89 & 7.03 & 0.048 & 220.59 & 21.5 & 0.0072 & 88.92 & 7.6 & 0.043 \\
\hline Station $(\mathrm{S})$ & 3.61 & 6.68 & 0.001 & 13.592 & 2.5 & n.s. & 10.7 & 5.1 & 0.017 \\
\hline $\mathrm{C} \times \mathrm{S}$ & 3.53 & 6.54 & $<0.001$ & 10.259 & 1.9 & n.s. & 10.7 & 5.1 & 0.006 \\
\hline Cochran's test transformation & & $C=0.44$ & $P>0.05$ & & $C=0.65$ & $P>0.05$ & & $C=0.33$ & $P>0.05$ \\
\hline & & None & & & None & & & None & \\
\hline
\end{tabular}

The response of adults, early recruits and late recruits was analysed for three stations $(d f=2)$ and three communities $(d f=2)$. The design was a two-way mixed model ANOVA (station was the random factor). Terms were considered not significant (n.s.) at $P>0.05$ 


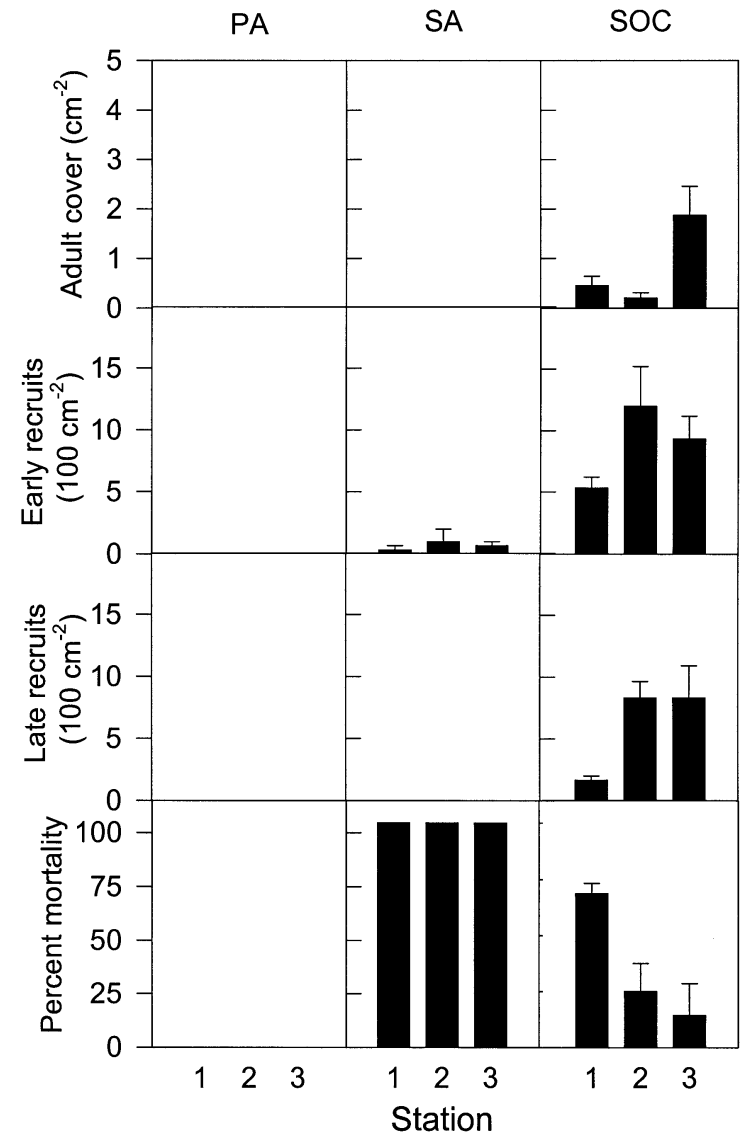

Fig. 1 Adult percentage cover $(n=20)$, May early-recruit abundance $(n=3)$, late-recruit abundance $(n=3)$, and percentage mortality among the three communities studied: $P A$ (photophilic algae), $S A$ (sciaphilic algae) and $S O C$ (semi-obscure caves). Differences among stations 1,2 , and 3 are shown. Vertical bars are standard errors

D. hispida recruits were found on the 15-day plate set corresponding to the storm period and very few invertebrate recruits were found in general. Several plates were lost (three in total) and many were seriously damaged possibly due to abrasion by suspended material.

None of the ancestrulae on the 15-day plates showed gemmae or secondary zooids. I did not find any skeletons of dead ancestrulae or grazing signs for the first 15 days. I did not observe contact with other organisms co-recruiting on the plates during the first 15 days.

Total numbers of Disporella hispida recruits varied along communities, stations and sampling periods (Table 2). Except for the notable peak in late October 1999, when recruits were recorded in the SA communities as well (Fig. 2), the SOC community plates were the most colonised by early recruits. Overall, station 2 had the highest number of early recruits, although differences with station 1 were not significant throughout the year. These results showed statistical significance for all double and triple interactions in the analysis of variance (Table 2).

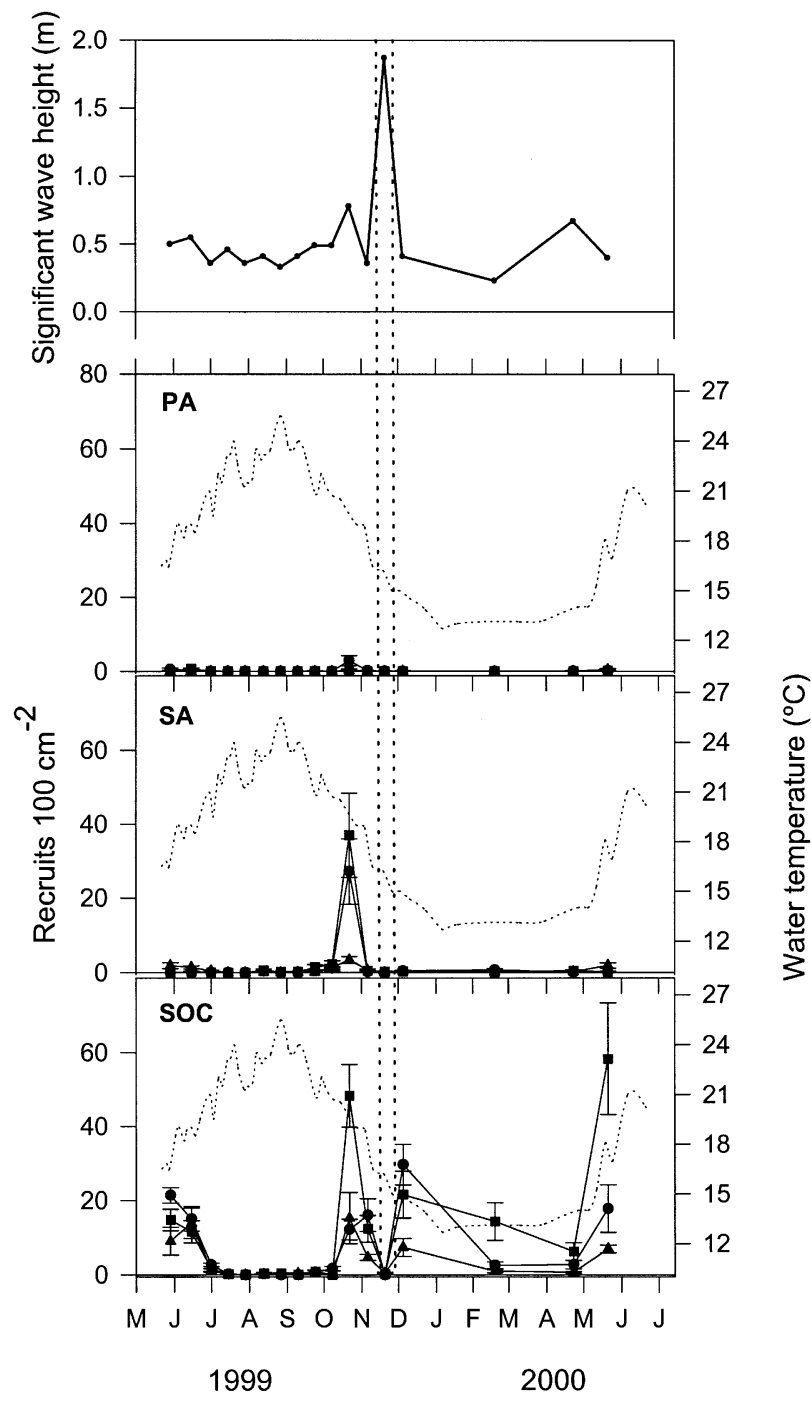

Fig. 2 Monthly time-course of significant wave height, water temperature, and early-recruit abundance on the PA, SA and SOC communities. Recruit abundance is shown for each station: $1(\mathbf{O})$, $2(\boldsymbol{\square})$, and $3(\mathbf{\Delta})$

Table 2 Results of the analysis of variance testing effects of sampling period, community, and station on the numbers of early recruits

\begin{tabular}{lrrr}
\hline Source of variation & \multicolumn{1}{c}{ MS } & \multicolumn{1}{l}{$F$} & \multicolumn{1}{l}{$P$} \\
\hline Sampling period & 21.83 & 31.8 & $<0.001$ \\
Community & 156.56 & 45.8 & 0.001 \\
Station & 4.88 & 21.4 & $<0.001$ \\
Period $\times$ Station & 0.68 & 2.9 & $<0.001$ \\
Period $\times$ Community & 11.07 & 11.8 & $<0.001$ \\
Station $\times$ Community & 3.42 & 14.9 & $<0.001$ \\
Period $\times$ Station $\times$ Community & 0.93 & 4.1 & $<0.001$ \\
\hline
\end{tabular}

Response of early recruits was analysed for 17 time points $(d f=16)$, three communities $(d f=2)$ and three stations $(d f=2)$. The design was a three-way mixed model ANOVA (station was the random factor). Variable was $\log (x+1)$ transformed, Cochran's test: $C=0.07, P>0.05$ 
Late recruitment, growth and mortality

The distribution of early recruits varied among communities (Table 1, Fig. 1), and ancestrulae were exclusively found in the SA and $\mathrm{SOC}$ communities $(\mathrm{SOC}>\mathrm{SA}=$ PA, SNK test).

The late recruitment plates showed different scenarios depending on the community considered. The PA community plates were almost totally covered with erect algae such as Padina pavonica (L.), Halopteris scoparia (L.), Dyctiota dichotoma (Hudson) var. intricata (C. Agardh), Jania corniculata (L.), Sphacelaria cirrosa (Roth) and Falkenbergia rufolanosa (Harvey). The bases of algal thalli trapped sediment, so that only a small proportion $(<1 \%)$ of the plate surface remained uncovered. The plates of the SA communities had both encrusting and erect algae. Among them, Aglaozonia parvula (Greville), Colpomenia sinuosa (Mertens), Sphacelaria cirrosa and Giraudia sphacelarioides (Derbès and Solier) dominated. Algal cover on the plates of the SOC communities was reduced in comparison to the other communities, mainly due to encrusting coralline algae and Cyanophyta. No identification to the species level was possible for those organisms. The main sessile invertebrates were polychaetes, barnacles, cheilostome bryozoans (see the above mentioned species) and, to a much lesser extent, the sponge Crambe crambe (Schmidt), particularly on the SOC community plates.

Growth of Disporella hispida colonies was not estimated in the PA and SA communities, since no survivors were found after 4 months (see Fig. 1). The majority of colonies were roughly circular, making approximate area easily calculable from the mean colony diameters. Colony areas on the SOC community plates were 0.41 $( \pm 0.32) \mathrm{cm}^{-2}$ at station $1,0.26( \pm 0.23)$ at station 2 , and $0.68( \pm 1.07)$ at station 3 .

The number of late recruits (survivors) varied between communities and stations (Table 1). Late recruits were only present in the SOC communities even though there were wide differences across stations (significant interaction term Community $\times$ Station). Mortality was $100 \%$ for the early colonies of the SA plates after 4 months (Fig. 1). Lower mortality rates were recorded among recruits from the SOC community plates. Recruits from station 1 showed the highest, those of station 3 the lowest. None of the colonies observed after a 4-month interval had been grazed and/or broken.

The relationship between numbers of dead colonies on the 4-month plates and on the 15-day plates was not significant $\left(r^{2}<0.5, P>0.05\right)$. Overgrowth by algae and/or other organisms was not observed, although contacts with co-recruiting invertebrates were recorded ( $1 \%$ total colonies). All the Disporella hispida recruits in contact with other sessile invertebrates showed the characteristic elevation of the colony margins shown in Fig. 3.

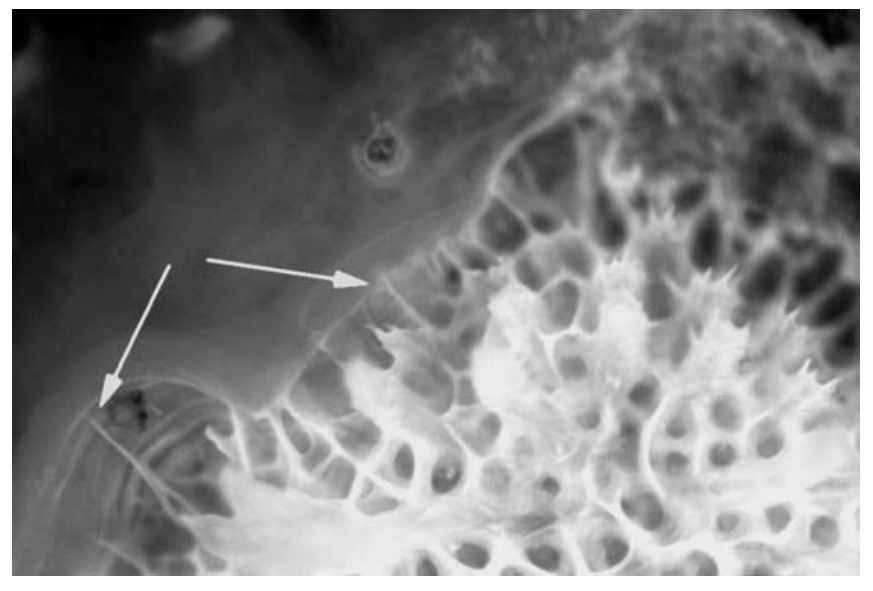

Fig. 3 Photograph of a 3-month-old Disporella hispida colony contacting the co-recruiting sponge Crambe crambe. As a response to threatening overgrowth by the sponge, the colony boundary is elevated and shows defence spines (arrows)

\section{Discussion}

One of the goals of this study was to determine Disporella hispida larval release periods by studying its early recruitment. The annual time course of recruit appearance reported here is the first observation on the larval release period of this species, and confirmation by long-term monitoring is necessary. Recruit appearance, and thus larval release, appear to be linked to changes in water temperature such as spring increments and autumn decrements.

Despite the proximity of the different communities on the boulder sides, the distribution of early recruits is non-random among communities and seems mainly determined by the vicinity of adult conspecifics, which occurs exclusively in the semi-obscure caves (SOC). This pattern can be the result of restricted dispersal due to the short life span and limited swimming abilities of larvae, to larval habitat choice, or to a combination of both factors (Keough 1989; Hurlbut 1991).

Although the highest recruit abundance was found in the SOC communities, some recruits could also be found in the SA communities and, to a much lesser extent, in the PA communities. This may result from strong hydrodynamic events capable of washing larvae out of the caves toward the water column, as it is indicated by a coincidence of increased wave heights during late October and recruitment outside the SOC communities. There is a "hydrodynamic limit" beyond which larvae of sessile invertebrates cannot control swimming direction and behave like passive particles (Underwood and Keough 2001). A much stronger influence of water turbulence on recruitment patterns is suggested by the coincidence of local storms and recruit disappearance recorded in November and December 1999. Settlement seems to be hindered when water turbulence is strong, possibly because larval attachment is difficult under these condi- 
tions (see Todd 1998). Nonetheless, the recruitment patterns observed during this period may also be the result of reduced parental reproductive activity, wider larval dispersal (dilution), and post-settlement mortality due to the effects of the storm.

The 15-day plates show early recruitment, not settlement. The observed differences in the abundance patterns of early recruits among the communities studied may be due to post-settlement mortality during the 15-day period rather than short-distance dispersal (philopatry) or habitat choice of larvae. Differential early post-settlement mortality may determine local differences in the abundance of sessile invertebrates such as colonial bryozoans (Keough and Downes 1982; Keough 1986; Keough and Chernoff 1987). Among the factors that may have affected mortality of Diporella hispida settlers are sedimentation, predation and competition for space with other organisms. Sediment accumulation was only recorded on the PA community plates and it was not uniform through time, while early recruits were scarce in these communities over the whole study period. Moreover, I did not find dead ancestrulae underneath the sediment, indicating that mortality due to sedimentation, if it occurred at all, would not alone explain the distribution of early recruits. It is much more plausible to suggest that the presence of a mobile substrate, such as sediment on the plates, brought about settlement failure.

Effects of large predators (e.g. fishes), which are capable of completely removing ancestrulae from the plates (see Keough 1986) are likely but unknown for Disporella hispida. Among large fish, some demersal Sparidae species are known to feed on colonial bryozoans in the NW Mediterranean, but feeding on D. hispida has not been reported (Sala and Ballesteros 1997). Moreover, large fishes can easily move between communities which are equally accessible to such predators at the study site. Large-fish preference for the colonies of one specific community is difficult to envisage. Small, slow moving invertebrates such as juveniles of sea stars are known to prey on cyclostomes (Day and Osman 1981) and young sea urchins, particularly Arbacia lixula (L.), feed on colonial bryozoans in the NW Mediterranean (J. Garrabou, personal communication). However, Day and Osman (1981) and Keough (1986) have emphasised that small predators such as sea star juveniles or nudibranchs (see Iyengar and Harvell 2002), generally leave skeletal remnants of the young colonies, an event not observed in this study. Moreover, A. lixula is very rare at the study site and other urchins are not abundant (personal observation). Therefore, it is unlikely that predation by small animals (e.g. benthic fishes, urchins, and other invertebrates) on young Disporella hispida colonies has caused a total or almost total removal of settlers from the PA and SA community plates during the first 15 days. In Bugula neritina (L.), for example, settler mortality is uniform across habitats during the first week of settlement (Keough 1986; Keough and Chernoff 1987). If settlers were evenly distributed among communities, only an extremely selective mortality would be responsible for the elimination of all or most settlers from the PA and SA communities. This is unlikely, considering that there was no sign of mortality or evidence for strong intra-, or inter-specific competition events during the first 15 days. Habitat-linked mortality events may become more important when the interactions among organisms co-recruiting on the settlement plates increase some weeks after settlement (see below).

While early recruitment was a good predictor of adult distribution among communities, severe post-recruitment mortality in the PA and SA communities and, to a lesser extent, at station 1 of the SOC communities, enhanced the coupling between recruit and adult distribution. Postrecruitment mortality was density-independent across the communities studied, and factors influencing mortality among recruits appeared mainly community-dependent. During summer 2001, the few colonies found in the SA communities died within 4 months. The scant colonies found in the PA and SA communities in the preliminary experiment of 2000 suffered the same fate. Although it was not tested in this study, it seems likely that high post-recruitment mortality may be responsible for the total disappearance from the PA and SA communities of the early colonies when these are abundant (e.g. autumn 1999). Nevertheless, the heavy recruitment recorded in October 1999 was possibly an extraordinary pulsed input of new individuals to the SA communities, more so if we consider that this was particularly relevant only at two stations (Fig. 2).

It is difficult to assess from this study the precise causes of the differential community dependent mortality observed. I have discussed above the possible effects of small and large predators, yet further experimentation is still required on possible predation on ancestrulae and young colonies of Disporella hispida. On the other hand, competition for space with fast-growing organisms such as algae seems to be more relevant in habitats where algae rapidly occupy free substrate, as in the PA and SA communities. Although algal overgrowth was not directly observed, the entire surface of the plates in the PA and, to a lesser extent, in the SA communities was covered by algae after 4 months. In the PA communities, space occupation by algal thalli and the associated sediment was likely to hinder not just growth and survival, but also settlement by $D$. hispida and sessile hard-substrate invertebrates in general. Disporella hispida, like other gymnolemates, colonises thalli of long-lived algae, and leaves and rhizomes of seagrasses (Zabala 1986), so that it might colonise algae rather than rocky substrate in the PA communities. However, the PA communities at the study site were dominated by short-lived algae with fast thallus turnover; these do not seem to be an appropriate settlement substrate for this species. Although several long-lived algal species (i.e. many encrusting corallines) were present in the SA communities, other species known to host $D$. hispida colonies were very rare (i.e. Halimeda, Udotea). The lack of suitable substrate for settling, coupled with short-distance dispersal, may be an important factor determining the absence of $D$. hispida 
in such communities at the study site. As regards the interactions with sessile invertebrates, polychaetes and sponges were observed in contact with and seeking to overgrow $D$. hispida colonies. Overall, overgrowth by other slow-growing sessile organisms (e.g. sponges) seems not to be a relevant cause of mortality for early colonies of $D$. hispida. This species is capable of counteracting overgrowth by elevating the colony margins (see Stebbing 1973), and the characteristic spines (Fig. 3) at the colony boundaries may also be an important defence mechanism.

Settlement and recruitment in habitats where the pressure of post-recruitment mortality is low, may have the advantage of optimising the reproductive effort of colonial invertebrate species that produce relatively few larvae (see Jackson 1986). In bryozoans releasing shortlived larvae, philopatry can account for most of the adult spatial distribution (Keough and Chernoff 1987). Hydrodynamic factors may allow short-lived larvae to disperse widely in non-parental habitats although from these results it appears that post-recruitment mortality limits the likelihood of permanently colonising such habitats.

In summary, patterns of spatial distribution in Disporella hispida seem to be principally maintained by differential recruitment in the communities where adults live at the study site. This seems to depend upon larval philopatry, due to either fast settlement or active habitat choice or both, and the low post-recruitment mortality occurring in parental communities.

Acknowledgements I am grateful to Xavier Turon, Iosune Uriz and Teresa Alcoverro for their help with the sampling design and for comments and criticism on early drafts. Thanks also go to Kike Ballesteros for the complex identification of the algal recruits, Rohan Arthur for corrections and suggestions, and to Quim Garrabou for providing information on some biological aspects of the species studied. Iolanda Abreu and Gustavo Carreras assisted me from the sea surface. Financial support came from a Marie Curie Research Training and the INTAS 971-854 grants.

\section{References}

Carlon DB, Olson RR (1993) Larval dispersal distance for adult spatial pattern in two Caribbean reef corals. J Exp Mar Biol Ecol 173:247-263

Davis AR, Butler AJ (1989) Direct observations of larval dispersal in the colonial ascidian Podoclavella moluccensis Sluiter: evidence for closed populations. J Exp Mar Biol Ecol 127:189-203

Day RW, Osman RW (1981) Predation by Patiria miniata (Asteroidea) on bryozoans: prey diversity may depend on the mechanism of succession. Oecologia 51:300-309

Dirnberger JM (1993) Dispersal of larvae with a short planktonic phase in the polychaete Spirorbis spirillum (Linneus). Bull Mar Sci 52:898-910

Fadlallah YH, Pearse JS (1982) Sexual reproduction in solitary corals: overlapping oogenic and brooding cycles, and benthic planulas in Balanophyllia elegans. Mar Biol 71:223-231

Gerrodette T (1981) Dispersal of the solitary coral Balanophyllia elegans by demersal planular larvae. Ecology 62:611-619

Harmelin JG (1976) The suborder Tubuliporina (Bryozoa Cyclostomata) in the Mediterranean: ecology and systematics. Mem Int Oceanogr Monaco 10:1-326
Hurlbut CJ (1991) The effects of larval abundance, settlement and juvenile mortality on the depth distribution of a colonial ascidian. J Exp Mar Biol Ecol. 150:183-202

Iyengar EV, Harvell CD (2002) Specificity of cues inducing defensive spines in the bryozoan Membranipora membranacea. Mar Ecol Prog Ser 225:205-218

Jackson JBC (1985) Distribution and ecology of clonal and aclonal benthic invertebrates. In: Jackson JBC, Buss LW, Cook E (eds) Population biology and evolution of clonal organisms. Yale University, New Haven, pp 297-356

Jackson JBC (1986) Modes of dispersal of clonal benthic invertebrates: consequences for species' distributions and genetic structure of local populations. Bull Mar Sci 39:588-606

Keough MJ (1984) Kin-recognition and the spatial distribution of larvae of the bryozoan Bugula neritina. Evolution 38:142-147

Keough MJ (1986) The distribution of a bryozoan on seagrass blades: settlement, growth and mortality. Ecology 67:846-857

Keough MJ (1989) Dispersal of the bryozoan Bugula neritina and effects of adults on newly metamorphosed juveniles. Mar Ecol Prog Ser 57:163-171

Keough MJ, Chernoff H (1987) Dispersal and population variation in the bryozoan Bugula neritina. Ecology 68:199-210

Keough MJ, Downes BJ (1982) Recruitment of marine invertebrates: the role of active larval choices and early mortality. Oecologia 54:348-352

Mariani S (2002) Larval supply and recruitment of invertebrates in the western Mediterranean: patterns in contrasting benthic communities. PhD thesis, University of Barcelona, Spain

Mariani S, Uriz MJ, Turon X (2000) Larval bloom of the oviparous sponge Cliona viridis: coupling of larval abundance and adult distribution. Mar Biol 137:783-790

Nielsen C (1970) On metamorphosis and ancestrula formation in cyclostomatous bryozoans. Ophelia 7:217-256

Olson RR (1985) The consequences of short-distance larval dispersal in a sessile marine invertebrate. Ecology 66:30-39

Ryland JS (1976) Behaviour, settlement and metamorphosis of bryozoan larvae: a review. Thalassia Jugosl 10:239-262

Sala E, Ballesteros E (1997) Partitioning of space and food resources by three fish of the genus Diplodus (Sparidae) in a Mediterranean rocky infralittoral ecosystem. Mar Ecol Prog Ser 152:273-283

Stebbing ARD (1973) Observations on colony overgrowth and spatial competition. In: Larwood GP (ed) Living and fossil Bryozoa. Academic Press, New York, pp 173-183

Stoner DS (1990) Recruitment of a tropical colonial ascidian: relative importance of pre-settlement vs. post-settlement processes. Ecology 71:1682-1690

Temkin MH, Zimmer RL (2002) Phylum Bryozoa. In: Young CM (ed) Atlas of marine invertebrate larvae. Academic Press, London, pp 411-428

Todd CD (1998) Larval supply and recruitment of benthic invertebrates: do larvae always disperse as much as we believe? Hydrobiologia 375/376:1-21

Turon X, Vázquez E (1996) A non-swimming larva: Prostyela longicauda (Styelidae). Inv Biol 115:331-342

Underwood AJ, Keough (2001) Supply-side ecology: the nature and consequences of variations in recruitment of intertidal organisms. In: Bertness MD, Gaines SD, Hay ME (eds) Marine community ecology. Sinauer, Sunderland, Mass., pp 183-200

Young CM, Chia FS (1987) Abundance and distribution of pelagic larvae as influenced by predation, behavior, and hydrogeographic factors. In: Giese AC (ed) Reproduction of marine invertebrates, vol 9. Blackwell Scientific, Palo Alto, Calif., pp 385-464

Zabala M (1986) Fauna dels briozous dels països catalans. Arxius de la Secció de Ciències LXXXIV, Institut d'Estudis Catalans, Barcelona

Zea S (1993) Recruitment of Demosponges (Porifera, Demospongiae) in rocky and coral reef habitats of Santa Marta, Colombian Carribean. PSZNI Mar Ecol 14:1-21 